\title{
Testes de envelhecimento acelerado e deterioração controlada na avaliação do vigor de aquênios de girassol
}

\author{
Accelerated aging and controlled deterioration seeds vigour tests for sunflower \\ Madelon Rodrigues Sá Braz ${ }^{\mathrm{I}}$ Camila Santos Barros ${ }^{\mathrm{II}}$ Fernanda Pereira Castro ${ }^{\mathrm{II}}$ \\ Claudia Antonia Vieira RossettoII
}

\section{RESUMO}

Os testes de vigor têm sido desenvolvidos para diferenciar os lotes de sementes devido às limitações impostas pelo teste de germinação. O objetivo do trabalho foi analisar a eficiência dos testes de envelhecimento acelerado e deterioração controlada na avaliação do vigor de lotes de aquênios de girassol. Para tanto, cinco lotes de aquênios (sementes com o pericarpo) de girassol da cultivar "Catissol 01 " foram submetidos à determinação do grau de umidade $e$ à avaliação da qualidade fisiológica, empregando os testes de germinação e vigor (primeira contagem, teste de frio, condutividade elétrica, emergência de plântulas, índice de velocidade de emergência, envelhecimento acelerado pelos sistemas tradicional e com solução saturada de $\mathrm{NaCl}$ a $42^{\circ} \mathrm{C}$ por 48, 72, 96 horas e deterioração controlada com teor inicial de água de 15, 20, 25\% por 48, 72, 96 horas a $42^{\circ} \mathrm{C}$ ). Os resultados permitiram concluir que o teste de envelhecimento acelerado com solução saturada de $\mathrm{NaCl}$ por 96 horas foi eficiente para classificar os lotes de aquênios de girassol. As combinações de $20 \%$ de água nos aquênios por 72 horas de exposição e de 25\% de água nos aquênios por 48 e 72 horas de exposição permitem classificar os lotes de aquênios de girassol.

Palavras-chave: Hellianthus annuus L., controle de qualidade, testes de vigor.

\section{ABSTRACT}

The vigour tests were developed to detect differences of seeds lots owing to limitations the germination test. This study was conducted to compare different procedures of the accelerated aging and controlled deterioration tests to evaluate sunflowers seed vigour. Five lots of sunflower achenes (seeds with pericarp) $\mathrm{cv}$. Catissol 01 were submitted to the water content test and to the evaluation of physiological quality using by germination and vigour test (first count, cold test, electrical conductivity, seedling emergence and speed of emergence index, accelerated aging with tradicional system and satured solution of $\mathrm{NaCl}$, at $42^{\circ} \mathrm{C}$ for 48, 72, 96 hours and controlled deterioration with 15, 20, 25\% water content for 48, 72, 96 hours at $42^{\circ} \mathrm{C}$ ). The results showed that the accelerated aging test with use of satured solution of $\mathrm{NaCl}$ for 96 hours was efficient to classify the sunflowers achenes lots. The combinations of $20 \%$ water in the achenes for 72 hours and the combination of $25 \%$ water in the achenes for 48 and 72 hours was efficient to classify the sunflowers achenes lots.

Key words: Hellianthus annuus L., quality control, vigour tests.

\section{INTRODUÇÃO}

O girassol (Helianthus annuus L.) destacase como a quinta oleaginosa em produção de grãos e a quarta em produção de óleo no mundo (VIEIRA, 2005). O estabelecimento da cultura se dá pela população de plantas provenientes de sementes com pericarpo (aquênios). Para a aquisição, as sementes devem apresentar o padrão mínimo de germinação de $75 \%$ (BRASIL, 2005). O teste de germinação, usado como rotina para avaliação da qualidade fisiológica das sementes, fornece informações sobre o potencial de uma amostra para germinar sob condições ótimas de ambiente (MARCOS FILHO, 1999a). No entanto, no campo, as sementes podem estar sujeitas às situações adversas, como temperatura inadequada, excesso ou deficiência hídrica, microrganismos, e com isso nem sempre há correlação entre os testes de germinação

IPrograma de Pós-graduação em Fitotecnia, Universidade Federal Rural do Rio de Janeiro (UFRRJ), 23890-000, Seropédica, RJ, Brasil. E-mail: madelonsa@hotmail.com. Autor para correspondência.

"Departamento de Fitotecnia, Instituto de Agronomia, UFRRJ, Seropédica, RJ. Brasil. 
com a emergência de plântulas em campo, o que conduz a uma superestimativa de qualidade (RODO et al., 2000). Assim, devido às limitações impostas pelo teste de germinação, no sentido de diferenciar os lotes de sementes, vêm sendo desenvolvidos os testes de vigor (MARCOS FILHO, 1999a).

Em girassol, foi constatado que, entre os métodos empregados para avaliação do vigor, os de condutividade elétrica e o de lixiviação de potássio não têm sido eficientes na avaliação de genótipos desta espécie, quando correlacionados com a emergência de plântulas em campo (ALBUQUERQUE et al., 2001). No entanto, outros testes de vigor vêm sendo estudados e recomendados para várias espécies. ADAMO et al. (1984) verificaram que o teste de envelhecimento acelerado, a $42^{\circ} \mathrm{C}$, por 48 horas foi adequado para avaliar o vigor das sementes desta espécie. No entanto, para ZELENER et al. (1990), os períodos ideais devem ser de 72 e 96 horas a $42^{\circ} \mathrm{C}$, para obter correlação positiva com a emergência de plântulas em campo. Além disso, na literatura há trabalhos com a proposta de alteração da metodologia de teste de envelhecimento acelerado, visando o controle de absorção de água por meio do uso de solução saturada na câmara de exposição. Em soja, MARCOS FILHO et al. (2000) e, em amendoim, ROSSETTO et al. (2004) constataram que o teste de envelhecimento acelerado com solução saturada foi eficiente em avaliar o potencial fisiológico das sementes. Por outro lado, diferenças no vigor de lotes de sementes também têm sido detectadas pelo teste de deterioração controlada. Em soja, ROSSETTO \& MARCOS FILHO (1995) verificaram que o teste de deterioração controlada em comparação ao de envelhecimento acelerado apresenta-se menos drástico, pois causa menor germinação das sementes, que são expostas às condições deste teste.

O objetivo do trabalho foi analisar a eficiência dos testes de envelhecimento acelerado e deterioração controlada na avaliação do vigor de lotes de aquênios de girassol.

\section{MATERIAL E MÉTODOS}

O experimento foi conduzido com cinco lotes de aquênios (sementes com o pericarpo) de girassol (Helianthus annus L.), da cultivar "Catissol 01", provenientes da Coordenadoria de Assistência Técnica Integral do Estado de São Paulo (CATI-SP). Após o recebimento, os aquênios foram armazenados por dois meses a $17^{\circ} \mathrm{C}$ e $50 \%$ de umidade relativa do ar - UR. As amostras de cada lote foram submetidas à determinação do grau de umidade e à avaliação da qualidade fisiológica empregando os testes de germinação e vigor. O grau de umidade foi realizado a $105 \pm 3^{\circ} \mathrm{C}$, durante 24 horas, utilizando-se quatro subamostras de 25 aquênios (BRASIL, 1992).

O teste de germinação foi realizado com quatro subamostras de 50 aquênios, utilizando substrato de papel tipo germitest, umedecido com água destilada e esterilizada, na proporção equivalente a 2,5 vezes a sua massa. Os rolos foram mantidos a $20-30^{\circ} \mathrm{C}$, na ausência de luz. As avaliações foram realizadas aos quatro e 10 dias (BRASIL, 1992). Em conjunto com o teste de germinação, foi realizado o teste de primeira contagem (NAKAGAWA, 1999).

Para o teste de frio, os aquênios foram mantidos por sete dias a $10^{\circ} \mathrm{C}$ na ausência de luz, (BARROS et al., 1999). Posteriormente, foi realizado o teste de germinação a $20-30^{\circ} \mathrm{C}$. As avaliações foram realizadas aos quatro e 10 dias (BRASIL, 1992).

O teste de condutividade elétrica foi realizado com quatro subamostras de 50 aquênios que primeiramente foram submetidas à remoção do pericarpo (ALBUQUERQUE et al., 2001). Em seguida, estas sementes foram imersas em $75 \mathrm{ml}$ de água destilada e deionizada, durante 24 horas a $25^{\circ} \mathrm{C}$ (VIEIRA \& KRZYZANOWSKI, 1999). Para a leitura, foi utilizado o aparelho da marca Meinsberg Conductivity Meter LF 37.

Para o teste de envelhecimento acelerado, 240 aquênios de cada lote foram dispostos em camada única, sobre tela de alumínio no interior de caixas plásticas do tipo gerbox, contendo no fundo $40 \mathrm{ml}$ de água destilada ou de solução saturada de $\mathrm{NaCl}(40 \mathrm{~g}$ $100 \mathrm{ml}^{-1}$ ). As caixas foram mantidas em câmara a $42^{\circ} \mathrm{C}$, por 48 (ADAMO et al., 1984), 72 e 96 horas (ZELENER et al., 1990). Após o período de exposição, foram realizadas a determinação do grau de umidade (BRASIL, 1992) e a instalação do teste de germinação, conforme descrito anteriormente. A avaliação foi realizada aos quatro dias após a instalação do teste (MARCOS FILHO, 1999b).

Para o teste de deterioração controlada, primeiramente as amostras de aquênios de cada lote foram subdivididas em três subamostras, visando ajustar o grau de umidade para 15, 20 e 25\%, por meiodo método do substrato úmido (ROSSETTO et al., 2004). Após atingirem o grau de umidade desejado, os aquênios foram acondicionados em recipientes de vidro e mantidos a $10^{\circ} \mathrm{C}$ por 12 horas (SANTOS et al., 2003). No final deste período, os aquênios foram submetidos à determinação do grau de umidade e foram acondicionados em embalagens de alumínio, previamente seladas. Estas embalagens foram mantidas a $42^{\circ} \mathrm{C}$, em sistema banho-maria, por 48, 72 e 96 horas. 
Após o período de exposição, as embalagens seladas foram imersas em água por 30 minutos e, em seguida, foram realizadas a determinação do grau de umidade (BRASIL, 1992) e a instalação do teste de germinação, conforme descrito anteriormente. A avaliação foi realizada aos quatro dias após a instalação do teste (MARCOS FILHO, 1999b).

O teste de emergência de plântulas em areia foi instalado com quatro subamostras de 50 aquênios de cada lote, que foram distribuídas em caixas plásticas contendo $7 \mathrm{~kg}$ de areia lavada, esterilizada e umedecida com água destilada, visando atingir $60 \%$ da capacidade de retenção (BRASIL, 1992). As caixas foram mantidas em ambiente sem controle. As avaliações foram realizadas aos 10 dias (NAKAGAWA, 1999).

Para o teste de emergência de plântulas em campo, foram utilizadas quatro subamostras de 100 aquênios cada lote, distribuídas em quatro linhas de cinco metros. A instalação foi realizada em fevereiro, em solo classificado como Planossolo (RAMOS et al., 1973). Foram realizadas contagens diárias no período de 21 dias, visando obter a porcentagem de plântulas emergidas. Conjuntamente, foi realizado o cálculo do índice de velocidade de emergência (MAGUIRE, 1962).

O delineamento experimental utilizado foi o inteiramente casualizado, com quatro repetições. Os dados foram submetidos à análise de variância após terem sido realizados os testes de Lilliefors e de Cochran e Bartlett (RIBEIRO JUNIOR, 2001). As médias foram comparadas pelo teste Tukey a 5\% de probabilidade. Realizou-se, também, a análise de correlação linear simples entre os resultados dos testes de vigor.

\section{RESULTADOS E DISCUSSÃO}

Pela análise da tabela 1 , foi constatado que os dados referentes ao grau de umidade dos aquênios foram semelhantes para os cinco lotes estudados. Este fato é importante na execução dos testes de vigor para a padronização das avaliações, pois, de acordo com MARCOS FILHO (2005), as sementes mais úmidas são mais sensíveis e sujeitas a uma deterioração mais intensa. Pelos testes de germinação e de emergência de plântulas em areia, não foram constatadas diferenças no desempenho entre os cinco lotes de aquênios de girassol. No entanto, pelo teste de emergência de plântulas em campo, quando as condições ambientais foram menos favoráveis à germinação desta espécie (temperatura média de $22^{\circ} \mathrm{C}$, ausência de precipitação pluvial após a semeadura e $206 \mathrm{~mm}$ entre o 8o e o 16음 dia após a instalação do teste), verificou-se comportamento distinto entre os lotes, destacando a superioridade do lote 4 e a inferioridade do lote 5 , diferindo do resultado obtido no teste de germinação. Para FREITAS et al. (2000), quando as condições de campo são favoráveis, os resultados do teste de germinação apresentam alta relação com a emergência de plântulas em campo. O teste de frio permitiu classificar os lotes 2 e 4 como o de melhor qualidade e o lote 5 como de qualidade inferior. Além disso, esse teste permitiu que os lotes 1 e 3 fossem classificados como de qualidade intermediária. No entanto, pelo teste de primeira contagem, foi possível classificar os lotes 3 e 4 como de qualidade superior. Pelo IVE foi classificado o lote 4 como de melhor qualidade e pelos dois testes o lote 2 foi classificado como de pior qualidade. Quando foram avaliados os aquênios sem o pericarpo (sementes), no teste de condutividade elétrica, foi observada somente a superioridade do lote 4 , a inferioridade dos lotes 1 , 3 e 5 e o nível intermediário do lote 2. ALBUQUERQUE et al. (2001) e LONGO et al. (1999) também constataram eficiência do teste de condutividade desta espécie após a remoção do pericarpo, uma vez que esta estrutura, sendo lignificada, é capaz de produzir um aumento da condutividade, prejudicando a avaliação.

Pelos resultados do teste de envelhecimento acelerado, empregando o sistema tradicional (Tabela 2), pode-se verificar que não houve diferença no

Tabela 1 - Dados médios de grau de umidade (GU), germinação (G), primeira contagem de germinação (PC), teste de frio (TF), emergência em areia (A), emergência em campo (EC) e índice de velocidade de emergência (IVE), obtidos de cinco lotes de aquênios de girassol.

\begin{tabular}{|c|c|c|c|c|c|c|c|c|}
\hline Lotes & GU (\%) & G (\%) & PC (\%) & TF (\%) & $\mathrm{CE}(\mu \mathrm{S} / \mathrm{cm} / \mathrm{g})$ & A (\%) & EC (\%) & IVE \\
\hline 1 & $5,7 a^{1}$ & 83a & 75ab & 69ab & $34,87 b$ & $94 a$ & 78ab & $12,1 \mathrm{bc}$ \\
\hline 2 & $5,8 a$ & $81 a$ & $68 b$ & $77 \mathrm{a}$ & $32,26 a b$ & $96 a$ & 77ab & 9,3d \\
\hline 3 & $6,1 a$ & $86 a$ & $78 a$ & 68ab & $40,38 b$ & $94 a$ & 80ab & $10,6 \mathrm{~cd}$ \\
\hline 4 & $6,0 a$ & $86 a$ & $78 a$ & $79 a$ & 26,03a & $98 a$ & 83a & $13,7 a$ \\
\hline 5 & $6,5 a$ & $80 a$ & 73ab & $61 b$ & $37,62 b$ & $94 a$ & $75 b$ & $12,4 \mathrm{ab}$ \\
\hline CV(\%) & 3,70 & 3,56 & 4,38 & 6,66 & 11,59 & 7,07 & 4,27 & 5,99 \\
\hline
\end{tabular}

${ }^{1}$ Médias seguidas pela mesma letra, minúscula na coluna, não diferem entre si pelo teste Tukey a 5\%. 
Tabela 2 - Dados médios de plântulas normais no teste de envelhecimento acelerado (\%) pelos sistemas tradicional e com solução saturada de $\mathrm{NaCl}$, por períodos de 48, 72 e 96 horas e, de grau de umidade (\%), obtidos de cinco lotes de aquênios de girassol.

\begin{tabular}{|c|c|c|c|c|c|c|}
\hline \multirow[b]{2}{*}{ Lotes } & \multicolumn{3}{|c|}{------------------Sistema tradicional------------------ } & \multicolumn{3}{|c|}{------------------Solução saturada------------------ } \\
\hline & $48 \mathrm{~h}$ & $72 \mathrm{~h}$ & $96 \mathrm{~h}$ & $48 \mathrm{~h}$ & $72 \mathrm{~h}$ & $96 \mathrm{~h}$ \\
\hline & \multicolumn{6}{|c|}{ Envelhecimento acelerado } \\
\hline 1 & $58 a b^{1}$ & 23a & $34 \mathrm{a}$ & 61ab & $40 a$ & $41 \mathrm{ab}$ \\
\hline 2 & $54 a b$ & $47 a$ & $20 b$ & $67 a$ & $58 a$ & $52 \mathrm{ab}$ \\
\hline 3 & $47 \mathrm{~b}$ & $47 \mathrm{a}$ & 33a & $40 c$ & $40 \mathrm{a}$ & $40 \mathrm{ab}$ \\
\hline 4 & $64 a$ & $46 a$ & 33a & $69 a$ & $53 a$ & $60 \mathrm{a}$ \\
\hline 5 & $54 a b$ & 23a & $17 b$ & $52 b$ & $27 a$ & $32 b$ \\
\hline \multirow[t]{2}{*}{ CV(\%) } & 9,97 & 30,06 & 19,22 & 10,07 & 33,27 & 21,85 \\
\hline & \multicolumn{6}{|c|}{ Grau de umidade } \\
\hline 1 & $15,5 a$ & 26,3a & $26,4 a$ & $6,6 c$ & $7,1 b$ & $7,2 \mathrm{ab}$ \\
\hline 2 & $16,0 \mathrm{a}$ & $22,6 a b$ & $27,7 \mathrm{a}$ & $6,7 b$ & 7,2ab & $6,9 b$ \\
\hline 3 & 14,3ab & $25,2 \mathrm{ab}$ & 25,9ab & $7,1 \mathrm{~b}$ & 7,2ab & $7,5 \mathrm{ab}$ \\
\hline 4 & $12,2 b$ & $22,9 b$ & $23,7 b$ & $6,9 b$ & $7,1 \mathrm{~b}$ & $7,1 \mathrm{~b}$ \\
\hline 5 & $16,2 \mathrm{a}$ & $25,2 \mathrm{ab}$ & $26,5 a$ & $7,4 a$ & 7,9a & 7,9a \\
\hline CV(\%) & 8,64 & 6,49 & 5,21 & 1,93 & 5,11 & 5,05 \\
\hline
\end{tabular}

${ }^{1}$ Médias seguidas pela mesma letra, minúscula na coluna, não diferem entre si pelo teste Tukey a 5\%.

desempenho entre os cinco lotes quando foi empregado o período de 72 horas. No entanto, empregando o período de 96 horas, os lotes 1, 3 e 4 apresentaram os melhores desempenhos e, os lotes 2 e 5 apresentaram os piores desempenhos. Assim, houve menor eficiência em separar os lotes, que foram classificados como de qualidade intermediária pelo teste de emergência de plântula em campo (Tabela 1). Com relação à condução do teste de envelhecimento acelerado com o uso da solução saturada (Tabela 2), foi observado que sob o período de 96 horas foi possível destacar o lote 4 como superior, o lote 5 como inferior e os lotes 1 , 2 e 3 como intermediários. Estes resultados são semelhantes aos do teste de emergência das plântulas em campo (Tabela 1). No procedimento tradicional do teste de envelhecimento acelerado (100\% UR), houve uma variação entre os valores máximos e mínimos do grau de umidade das sementes de 3,7 pontos percentuais depois da exposição de 72 horas e de 4,0 pontos percentuais após 48 e 96 horas. No entanto, de acordo com MARCOS FILHO (1999b), estas variações até o limite máximo de 4,0\% entre as amostras são toleráveis e não comprometem o resultado do teste. Por outro lado, com o emprego da solução salina, foram observados valores menores e mais uniformes do grau de umidade, revelando que o uso da solução saturada conseguiu retardar a absorção de água das sementes. Para MARCOS FILHO et al. (2001), as condições de envelhecimento com o uso de solução saturada promoveram efeitos menos drásticos em relação ao normalmente verificado com o uso do método tradicional.
O teste de deterioração controlada (Tabela 3), empregando a combinação de 72 horas de exposição com aquênios com teor inicial de água de $20 \%$, permitiu que o lote 4 fosse classificado como superior, o 5 como inferior e os lotes 1, 2 e 3 como intermediários. Estes resultados são semelhantes aos do teste de emergência de plântulas em campo (Tabela 1) e aos do teste de envelhecimento com o uso da solução saturada (Tabela 2). Também empregando a combinação de 48 e 72 horas de exposição com aquênios com teor de água de $25 \%$ foi possível classificar o lote 4 como superior, o lote 5 como inferior e os lotes 1, 2 e 3 como intermediários.

Com relação aos dados referentes ao grau de umidade dos aquênios após o período de exposição ao teste de deterioração controlada (Tabela 3), podese observar que os aquênios mantiveram aproximadamente o mesmo grau de umidade em relação ao início do teste. PANOBIANCO \& MARCOS FILHO (2001) também citam que o teste de deterioração incorpora melhor o controle do grau de umidade da semente e da temperatura durante a deterioração.

Houve correlação significativa entre o teste de emergência das plântulas em campo com o de condutividade elétrica das sementes sem o pericarpo, o de envelhecimento com solução saturada e tradicional por 96 horas e o de deterioração controlada (20\%/72 horas, 25\%/48 horas e 25\%/72 horas) (Tabelas 4 e 5). Também ÁVILAet al. (2005)e TEKRONY \& EGLI(1977), avaliando o vigor de sementes de canola e de soja, respectivamente, relataram que houve correlação significativa entre o teste de envelhecimento acelerado tradicional e a emergência de plântulas no campo. Além 
Testes de envelhecimento acelerado e deterioração controlada na avaliação do vigor de aquênios de girassol.

Tabela 3 - Dados médios de plântulas normais (\%) no teste de deterioração controlada, por períodos de 48, 72 e 96 horas, com sementes com teor inicial de água de 15, 20 e 25\% e, de grau de umidade (\%), obtidos de cinco lotes de aquênios de girassol.

\begin{tabular}{|c|c|c|c|c|c|c|c|c|c|}
\hline \multirow{2}{*}{ Lotes } & \multicolumn{3}{|c|}{---------------15\%--------------- } & \multicolumn{3}{|c|}{---------------20\%--------------- } & \multicolumn{3}{|c|}{---------------25\%--------------- } \\
\hline & $48 \mathrm{~h}$ & $72 \mathrm{~h}$ & $96 h$ & $48 \mathrm{~h}$ & $72 \mathrm{~h}$ & $96 \mathrm{~h}$ & $48 \mathrm{~h}$ & $72 \mathrm{~h}$ & $96 \mathrm{~h}$ \\
\hline & \multicolumn{9}{|c|}{ Deterioração controlada } \\
\hline 1 & $58 a^{1}$ & $65 a$ & $48 a$ & $46 \mathrm{ab}$ & $63 a b$ & $55 a$ & $34 b$ & $54 \mathrm{~b}$ & $52 a$ \\
\hline 2 & $59 a$ & 53bc & $50 a$ & 54ab & 61ab & $48 a$ & 30bc & $45 b c$ & $48 a$ \\
\hline 3 & $31 a$ & 52cd & $49 a$ & $31 b$ & 53bc & $48 a$ & 20bc & $35 c$ & $26 b$ \\
\hline 4 & $56 a$ & 63ab & $51 \mathrm{a}$ & $59 a$ & $69 a$ & $45 a$ & $57 a$ & $65 a$ & $50 \mathrm{a}$ \\
\hline 5 & $47 a$ & $42 d$ & $35 b$ & $31 b$ & $47 c$ & $24 b$ & $13 c$ & $20 d$ & $11 \mathrm{~b}$ \\
\hline \multirow[t]{2}{*}{$\mathrm{CV}(\%)$} & 30,22 & 8,42 & 8,26 & 23,90 & 8,66 & 12,08 & 25,18 & 10,42 & 12,77 \\
\hline & \multicolumn{9}{|c|}{ Grau de umidade } \\
\hline 1 & $14,6 b$ & $15,0 \mathrm{a}$ & $15,4 \mathrm{a}$ & $19,4 \mathrm{a}$ & $20,1 \mathrm{a}$ & $19,6 a$ & $25,2 \mathrm{a}$ & $25,1 \mathrm{ab}$ & $25,0 a b$ \\
\hline 2 & $14,3 b$ & $14,5 \mathrm{a}$ & $14,3 a$ & $20,1 \mathrm{a}$ & $20,0 a$ & $19,6 a$ & $25,1 \mathrm{a}$ & $24,6 a$ & $25,1 \mathrm{a}$ \\
\hline 3 & $15,6 a$ & $15,0 \mathrm{a}$ & $14,4 \mathrm{a}$ & $19,5 a$ & $19,1 \mathrm{a}$ & $20,0 \mathrm{a}$ & $24,6 a$ & $25,5 b$ & $24,1 b$ \\
\hline 4 & $15,6 \mathrm{a}$ & $14,0 \mathrm{a}$ & $15,1 \mathrm{a}$ & $19,7 \mathrm{a}$ & $19,3 a$ & $20,2 a$ & $23,1 \mathrm{a}$ & $24,3 a$ & $24,7 a b$ \\
\hline 5 & 15,0ab & $15,1 \mathrm{a}$ & $15,0 \mathrm{a}$ & $20,1 \mathrm{a}$ & $20,2 \mathrm{a}$ & $20,1 \mathrm{a}$ & $24,1 \mathrm{a}$ & $24,9 a b$ & $25,2 \mathrm{a}$ \\
\hline $\mathrm{CV}(\%)$ & 2,96 & 4,78 & 4,87 & 2,83 & 2,86 & 3,09 & $2,94 a$ & 1,88 & 1,65 \\
\hline
\end{tabular}

${ }^{1}$ Médias seguidas pela mesma letra, minúscula na coluna, não diferem entre si pelo teste Tukey a 5\%.

disso, ÁVILA et al. (2005) observaram correlação significativa entre o teste de condutividade elétrica com o teste de emergência de plântulas em campo.

\section{CONCLUSÕES}

O teste de envelhecimento acelerado com solução saturada de $\mathrm{NaCl}$ por 96 horas foi eficiente para classificar os lotes de aquênios de girassol. As combinações de $20 \%$ de água nos aquênios por 72 horas de exposição e de $25 \%$ de água nos aquênios por 48 e 72 horas de exposição permitem classificar os lotes de aquênios de girassol.

\section{AGRADECIMENTOS}

Todos os autores agradecem ao Conselho Nacional de Desenvolvimento Científico e Tecnológico (CNPq), pela concessão das bolsas.

Tabela 4 - Coeficiente de correlação simples entre os resultados de deterioração controlada (DC) em relação aos testes de germinação (G), primeira contagem (PC), teste de frio (TF), emergência em areia (A), emergência em campo (EC) e índice de velocidade de emergência (IVE).

\begin{tabular}{lllllll}
\hline & G & PC & TF & A & EC & IVE \\
\hline DC-15\%/48h & $-0,037^{\text {n.s }}$ & $0,049^{\text {n.s }}$ & $0,223^{\text {n.s }}$ & $-0,070^{\text {n.s }}$ & $-0,342^{\text {n.s }}$ & $0,234^{\text {n.s }}$ \\
DC-15\%/72h & $0,348^{\text {n.s }}$ & $0,247^{\text {n.s }}$ & $0,410^{*}$ & $0,122^{\text {n.s }}$ & $0,232^{\text {n.s }}$ & $0,296^{\text {n.s }}$ \\
DC-15\%/96h & $0,351^{\text {n.s }}$ & $0,065^{\text {n.s }}$ & $0,629^{* *}$ & $0,161^{\text {n.s }}$ & $0,519^{* *}$ & $-0,198^{\text {n.s }}$ \\
DC-20\%/48h & $0,275^{\text {n.s }}$ & $0,021^{\text {n.s }}$ & $0,553^{* *}$ & $0,647^{* *}$ & $0,170^{\text {n.s }}$ & $0,131^{\text {n.s }}$ \\
DC-20\%/72h & $0,223^{\text {n.s }}$ & $0,077^{\text {n.s }}$ & $0,567^{* *}$ & $0,126^{\text {n.s }}$ & $0,440^{*}$ & $0,175^{\text {n.s }}$ \\
DC-20\%/96h & $0,314^{\text {n.s }}$ & $0,083^{\text {n.s }}$ & $0,399^{*}$ & $0,158^{\text {n.s }}$ & $0,423^{*}$ & $-0,234^{\text {n.s }}$ \\
DC-25\%/48h & $0,300^{\text {n.s }}$ & $0,186^{\text {n.s }}$ & $0,570^{* *}$ & $0,487^{*}$ & $0,593^{* *}$ & $0,403^{*}$ \\
DC-25\%/72h & $0,355^{\text {n.s }}$ & $0,156^{\text {n.s }}$ & $0,636^{* *}$ & $0,276^{\text {n.s }}$ & $0,616^{* * *}$ & $0,311^{\text {n.s }}$ \\
DC-25\%/96h & $0,315^{\text {n.s }}$ & $-0,022^{\text {n.s }}$ & $0,641^{\text {n. }}$ & $0,306^{\text {n.s }}$ & $0,374^{\text {n.s }}$ & $-0,001^{\text {n.s }}$ \\
G & - & $0,699^{* * *}$ & $0,233^{\text {n.s }}$ & $0,328^{\text {n.s }}$ & $0,405^{*}$ & $0,126^{\text {n.s }}$ \\
PC & - & - & $-0,082^{\text {n.s }}$ & $0,004^{\text {n.s }}$ & $0,251^{\text {n.s }}$ & $0,448^{*}$ \\
TF & - & - & - & $0,337^{\text {n.s }}$ & $0,481^{*}$ & $-0,171^{\text {n.s }}$ \\
A & - & - & - & - & $0,279^{\text {n.s }}$ & $0,059^{\text {n.s }}$ \\
EC & - & - & - & - & - & - \\
IVE & - & - & - & - & - & $0,217^{\text {n.s }}$ \\
\hline
\end{tabular}

n.s não-significativo, ${ }^{* *}$ significativo a $1 \%$, e ${ }^{*}$ significativo a $5 \%$ de probabilidade. 
Tabela 5 - Coeficiente de correlação simples entre os resultados de deterioração controlada (DC), de germinação (G), de primeira contagem (PC), de teste de frio (TF), de emergência em areia (A), de emergência em campo (EC) e de índice de velocidade de emergência (IVE), em relação aos testes de condutividade elétrica (CE) e de envelhecimento acelerado (EA).

\begin{tabular}{|c|c|c|c|c|c|c|c|}
\hline & CE & $\mathrm{EA}-48 \mathrm{~h} / \mathrm{H}_{2} \mathrm{O}$ & $\mathrm{EA}-72 \mathrm{~h} / \mathrm{H}_{2} \mathrm{O}$ & EA-96h/ $\mathrm{H}_{2} \mathrm{O}$ & $\mathrm{EA}-48 \mathrm{~h} / \mathrm{NaCl}$ & $\mathrm{EA}-72 \mathrm{~h} / \mathrm{NaCl}$ & EA-96h/NaCl \\
\hline DC-15\%/48h & $-0,499^{*}$ & $0,268^{\mathrm{n} . \mathrm{s}}$ & $0,205^{\mathrm{n} . \mathrm{s}}$ & $-0,012^{\mathrm{n} . \mathrm{s}}$ & $0,650^{* *}$ & $0,311^{\mathrm{n} . \mathrm{s}}$ & $0,321^{\mathrm{n} . \mathrm{s}}$ \\
\hline DC-15\%/72h & $-0,360^{\text {n.s }}$ & $0,554^{* *}$ & $0,228^{\mathrm{n} . \mathrm{s}}$ & $0,622^{* *}$ & $0,493^{\mathrm{n} . \mathrm{s}}$ & $0,380^{\mathrm{n} . \mathrm{s}}$ & $0,457^{*}$ \\
\hline DC-15\%/96h & $-0,417^{*}$ & $0,165^{\mathrm{n} . \mathrm{s}}$ & $0,459^{*}$ & $0,433^{*}$ & $0,192^{\mathrm{n} . \mathrm{s}}$ & $0,308^{\mathrm{n} . \mathrm{s}}$ & $0,383^{*}$ \\
\hline DC-20\%/48h & $-0,853^{* *}$ & $0,593^{* *}$ & $0,100^{\mathrm{n} . \mathrm{s}}$ & $-0,061^{\text {n.s }}$ & $0,582^{* *}$ & $0,273^{\mathrm{n} . \mathrm{s}}$ & $0,304^{\mathrm{n} . \mathrm{s}}$ \\
\hline DC-20\%/72h & $-0,423^{*}$ & $0,513^{*}$ & $0,486^{*}$ & $0,460^{*}$ & $0,703^{* *}$ & $0,647^{* *}$ & $0,736^{* *}$ \\
\hline DC-20\%/96h & $-0,186^{\mathrm{n} . \mathrm{s}}$ & $-0,028^{\mathrm{n} . \mathrm{s}}$ & $0,127^{\mathrm{n} . \mathrm{s}}$ & $0,505^{*}$ & $0,154^{\mathrm{n} . \mathrm{s}}$ & $0,315^{\text {n.s }}$ & $0,242^{\mathrm{n} . \mathrm{s}}$ \\
\hline DC-25\%/48h & $-0,672^{* *}$ & $0,556^{*}$ & $0,289^{\text {n.s }}$ & $0,426^{*}$ & $0,567^{*}$ & $0,397^{*}$ & $0,574^{* *}$ \\
\hline DC-25\%/72h & $-0,587^{* *}$ & $0,528^{* *}$ & $0,459^{*}$ & $0,556^{* *}$ & $0,605^{* *}$ & $0,485^{*}$ & $0,623^{* *}$ \\
\hline DC-25\%/96h & $-0,593^{* *}$ & $0,434^{*}$ & $0,317^{\mathrm{n} . \mathrm{s}}$ & $0,439^{*}$ & $0,648^{*}$ & $0,430^{*}$ & $0,459^{*}$ \\
\hline G & $-0,294^{\mathrm{n} . \mathrm{s}}$ & $-0,052^{\mathrm{n} . \mathrm{s}}$ & $-0,049^{\text {n.s }}$ & $0,505^{*}$ & $-0,093^{\mathrm{n} . \mathrm{s}}$ & $0,089^{\mathrm{n} . \mathrm{s}}$ & $0,061^{\mathrm{n} . \mathrm{s}}$ \\
\hline PC & $-0,151^{\text {n.s }}$ & $0,028^{\mathrm{n} . \mathrm{s}}$ & $-0,098^{\text {n.s }}$ & $0,389^{*}$ & $-0,164^{\text {n.s }}$ & $0,005^{\mathrm{n} . \mathrm{s}}$ & $0,035^{\mathrm{n} . \mathrm{s}}$ \\
\hline $\mathrm{TF}$ & $-0,609^{* *}$ & $0,434^{*}$ & $0,473^{*}$ & $0,137^{\mathrm{n} . \mathrm{s}}$ & $0,363^{\mathrm{n} . \mathrm{s}}$ & $0,305^{\mathrm{n} . \mathrm{s}}$ & $0,522^{*}$ \\
\hline A & $-0,559^{* *}$ & $0,350^{\text {n.s }}$ & $-0,107^{\text {n.s }}$ & $-0,189^{\text {n.s }}$ & $0,217^{\text {n.s }}$ & $0,046^{\mathrm{n} . \mathrm{s}}$ & $0,056^{\mathrm{n} . \mathrm{s}}$ \\
\hline EC & $-0,479^{*}$ & $0,201^{\mathrm{n} . \mathrm{s}}$ & $0,186^{\mathrm{n} . \mathrm{s}}$ & $0,449^{*}$ & $0,043^{\mathrm{n} . \mathrm{s}}$ & $0,174^{\mathrm{n} . \mathrm{s}}$ & $0,416^{*}$ \\
\hline IVE & $-0,314^{\mathrm{n} . \mathrm{s}}$ & $0,427^{*}$ & $-0,083^{\mathrm{n} . \mathrm{s}}$ & $0,262^{\mathrm{n} . \mathrm{s}}$ & $0,268^{\mathrm{n} . \mathrm{s}}$ & $-0,061^{\text {n.s }}$ & $0,097^{\mathrm{n} . \mathrm{s}}$ \\
\hline $\mathrm{CE}$ & - & $-0,568^{* *}$ & $-0,162^{\mathrm{n} . \mathrm{s}}$ & $-0,014^{\mathrm{n} . \mathrm{s}}$ & $-0,591^{* *}$ & $-0,173^{\mathrm{n} . \mathrm{s}}$ & $-0,366^{\mathrm{n} . \mathrm{s}}$ \\
\hline
\end{tabular}

${ }^{\text {n.s }}$ não-significativo, ${ }^{* *}$ significativo a $1 \%$, e * significativo a $5 \%$ de probabilidade.

\section{REFERÊNCIAS}

ADAMO, P.E. et al. Comportamento germinativo de sementes de girassol submetidas ao teste de envelhecimento precoce. Revista Brasileira de Sementes, Brasília, v.6, n.3, p.15-20, 1984.

ALBUQUERQUE, M.C.de F. et al. Testes de condutividade elétrica e de lixiviação de potássio na avaliação da qualidade fisiológica de sementes de girassol. Revista Brasileira de Sementes, Brasília, v.23, n.1, p.1-8, 2001.

ÁVILA M.R. et al. Testes de laboratório em sementes de canola e a correlação com a emergência das plântulas em campo. Revista Brasileira de Sementes, Brasília, v.27, n.1, p.6276, 2005.

BARROS, A.S.R. et al. Teste de frio . In: KRZYZANOWSKI, F.C. et al. Vigor de sementes: conceitos e testes. Londrina: ABRATES, 1999. p.5.1-5.15.

BRASIL. Ministério da Agricultura e Reforma Agrária. Regras para análise de sementes. Brasília: SNDA/DNDV/CLAV, 1992. 365p.

BRASIL. Instrução Normativa $\mathrm{n}^{\circ} 25$, de 16 de dezembro de 2005. Diário Oficial da República Federativa do Brasil. Poder Executivo, Brasília, DF, 16 dez. 2005.

FREITAS, R.A. de. et al. Correlação entre testes para avaliação da qualidade de sementes de algodão e a emergência das plântulas em campo. Revista Brasileira de Sementes, Brasília, v.22, n.1, p.97-103, 2000.

LONGO, O. et al. Efecto de la presencia de pericarpo sobre los valores de conductividad em semillas de girasol (Helianthus annuus L.) com diferentes niveles de deterioro. Informativo ABRATES, Curitiba, v.9, n.1/2, p.149, 1999.

MAGUIRE, J.D. Speed of germination and in selection and evaluation for seedlings emergence and vigor. Crop Science, New York, v.2, p.176-177, 1962.

MARCOS FILHO, J. Fisiologia de plantas cultivadas. Piracicaba: Fealq, 2005. 495p.

MARCOS FILHO, J. Testes de vigor: Importância e utilização. In: KRZYZANOWSKI, F.C. et al. Vigor de sementes: conceitos e testes. Londrina: ABRATES, 1999a. p.1.1-1.20.

MARCOS FILHO, J. Testes de envelhecimento acelerado. In: KRZYZANOWSKI, F.C. et al. Vigor de sementes: conceitos e testes. Londrina: ABRATES, 1999b. p.3.1-3.21.

MARCOS FILHO, J. et al. Tamanho das sementes e o teste de envelhecimento acelerado para soja. Scientia Agricola, Piracicaba, v.57, n.3, p.473-482, 2000.

MARCOS FILHO, J. et al. Testes de envelhecimento acelerado e de deterioração controlada para avaliação do vigor de sementes de soja. Scientia Agricola, Piracicaba, v.58, n.2, p.421-426, 2001.

NAKAGAWA, J. Testes de vigor baseados na avaliação das plântulas. In: KRZYZANOWSKI, F.C. et al. Vigor de sementes: conceitos e testes. Londrina: ABRATES, 1999. p. $2.1-2.21$.

PANOBIANCO, M.; MARCOS FILHO, J. Envelhecimento acelerado e deterioração controlada em sementes de tomate. Scientia Agricola, Piracicaba, v.58, n.3, p.525-531, 2001.

Ciência Rural, v.38, n.7, out, 2008. 
RAMOS, D.P. et al. Levantamento detalhado de solos da área da Universidade Federal Rural do Rio de Janeiro. Pesquisa Agropecuária Brasileira, Brasília, v.38, n.6, p.1-27, 1973.

RIBEIRO JÚNIOR, J.I. Análises estatísticas no SAEG. 19.ed. Viçosa: UFV, 2001. 301p.

RODO, A.B. et al. Metodologia alternativa do teste de envelhecimento acelerado para sementes de cenoura. Scientia Agricola, Piracicaba, v.57, n.2, p.289-292, 2000.

ROSSETTO, C.A.V. et al. Envelhecimento acelerado e deterioração controlada em semente de amendoim. Pesquisa Agropecuária Brasileira, Brasília, v.39, n.8, p.795-801, 2004 .

ROSSETTO, C.A.V.; MARCOS FILHO, J. Comparação entre os métodos de envelhecimento acelerado e de deterioração controlada para avaliação da qualidade fisiológica de sementes de soja. Scientia Agricola, Piracicaba, v.52, n.1, p.123-131, 1995.
SANTOS, C.M. et al. Teste de deterioração controlada para avaliação do vigor de sementes de feijão. Revista Brasileira de Sementes, Brasília, v.25, n.2, p.28-35, 2003.

TEKRONY, D.M.; EGLI, D.B. Relationship between laboratory índices of soybean seed vigor and field emergence. Crop Science, Madison, v.17, n.4, p.573-577, 1977

VIEIRA, O.V. Ponto de maturação ideal para colheita do girassol visando alta qualidade da semente. 2005. 93f. Tese (Doutorado em Agronomia) - Universidade Federal do Paraná.

VIEIRA, R.D.; KRZYZANOWSKI, F.C. Teste de condutividade elétrica. In: KRZYZANOWSKI, F.C. et al. Vigor de sementes: conceitos e testes. Londrina: ABRATES, 1999. p. 4,1-4,26.

ZELENER, N. et al. Prueba de invejecimiento acelerado en girasol (Helianthus annuus L.) e interpretación de sus resultados. In: SEMINARIO PANAMERICANO DE SEMILLAS, 13., 1990, Guatemala. Acta... Guatemala:FELAS, 1990. n.p. 